\title{
Challenges in the development of a widely applicable method for sugarcane (Saccharum spp.) shoot tip cryopreservation
}

\author{
G.M. Volk' ${ }^{1, a}$, M.M. Jenderek ${ }^{1}$, E. Staats ${ }^{1}$, A. Shepherd ${ }^{1}$, R. Bonnart ${ }^{1}$, A. Ledo ${ }^{2}$ and T. Ayala-Silva ${ }^{3}$
}

1 USDA-ARS National Laboratory for Genetic Resources Preservation, 1111 S. Mason St., Fort Collins, C0 80521, USA; ${ }^{2}$ Embrapa Coastal Tablelands, A. Beira Mar, 3250 Jardins, Caixa Postal 44-Aracaju, SE 49025-040, Brazil; 3Tropical Agriculture Research Station, 2200 P.A. Campos Ave., Ste 201. Mayaguez, 006805470, Puerto Rico.

\begin{abstract}
The USDA-ARS National Plant Germplasm System (NPGS) maintains 946 accessions of sugarcane (Saccharum spp.) in the field at the Subtropical Horticulture Research Station in Miami, Florida. These accessions are particularly vulnerable to hurricanes, diseases, and other threats. We sought to identify a method whereby clonally propagated sugarcane accessions could be successfully introduced into tissue culture, multiplied, and then cryopreserved as shoot tips for long-term preservation at the National Laboratory for Genetic Resources Preservation in Fort Collins, Colorado. For many accessions, $\mathbf{7 0 \%}$ isopropyl alcohol and $20 \%$ commercial bleach treatments, followed by three rinses of sterile water were sufficient to remove microbial contaminants during the introduction process. However, in some cases, cefotaxime was particularly effective for removing bacterial contamination. We found that antioxidant treatments of glutathione, glycine betaine, and ascorbic acid did not improve regrowth after liquid nitrogen exposure using either PVS2 or PVS3 as cryoprotectants in droplet vitrification cryopreservation methods. Exposure durations of PVS2 and PVS3 were optimized, with and without exposure to liquid nitrogen (LN), and shoot tip regrowth levels ranged from 0 to $37 \%$ after $L N$ exposure. Published methods for encapsulation-dehydration and V-plate vitrification cryopreservation procedures were tested to determine if acceptable results could be obtained. Using these methods, shoot tip regrowth levels ranged from 0 to $50 \%$ after LN exposure. We conclude that the sugarcane cryopreservation methods that we tested are not yet ready for implementation in the NPGS.
\end{abstract}

Keywords: sugarcane, conservation, in vitro

\section{INTRODUCTION}

The USDA-ARS National Plant Germplasm System (NPGS) maintains a field collection of sugarcane at the Subtropical Horticulture Research Station (SHRS) in Miami, Florida. This collection currently has 946 accessions representing 17 species. In the field, sugarcane accessions lose vigor over time and must be periodically replaced. In addition, environmental disasters such as hurricanes and pathogens threaten the field collection, so we endeavored to secure this collection at the National Laboratory for Genetic Resources Preservation (NLGRP) in Fort Collins, Colorado. In vitro "medium term" storage conditions have been established for sugarcane; however, these methods require that cultures be transferred at six month intervals, which is prohibitive with respect to labor costs. In addition, cultures are kept in growth chambers at $16^{\circ} \mathrm{C}$, which are at risk of overheating, causing lethal damage to the cultures.

Early literature demonstrated the successful cryopreservation of sugarcane suspension cells, somatic embryos, and embryogenic calli (Finkle and Ulrich, 1982; Eksomtramage et al., 1992; Martínez-Montero et al., 1998). It would be extremely time consuming and difficult to convert the NPGS sugarcane collection into suspension cells,

aE-mail: Gayle.Volk@ars.usda.gov 
somatic embryos, or embryogenic calli prior to its cryopreservation. In addition, somaclonal variation may occur when accessions are converted to cell cultures.

Cryopreservation techniques that make use of shoot tips excised from in vitro-grown plants have been published for many genera, including Saccharum. Paulet et al. (1993), González-Arnao et al. (1999), González-Arnao and Engelmann (2006) and Melo et al. (2011) all published encapsulation-dehydration methods that demonstrated successful cryopreservation of sugarcane cultures. These techniques precultured shoot tips on medium supplemented with 0.5 to $0.75 \mathrm{M}$ sucrose prior encapsulation in calcium-alginate beads. Beads were then dehydrated to moisture contents of 20 to $25 \%$, and then plunged into liquid nitrogen (LN). Regrowth levels were highly variable, ranging from 14 to $91 \%$ for $S$. officinarum cultivars (Paulet et al., 1993; González-Arnao et al., 1999; González-Arnao and Engelmann, 2006; Melo et al., 2011).

Published droplet-vitrification cryopreservation methods report the successful cryopreservation of sugarcane using PVS2 (Sakai et al., 1990) as the cryoprotectant. Nogueira et al. (2013) found that 1-2 mm sugarcane shoot tips treated with a 20 min PVS2 exposure had survival levels of 20\% (Nogueira et al., 2013). Kaya and Souza (2017) compared droplet-vitrification and encapsulation using three sugarcane cultivars and found that a 45-min treatment with PVS2 at $0^{\circ} \mathrm{C}$ resulted in regrowth levels of 63 to $76 \%$ after LN exposure. The V-cryo-plate cryopreservation results published by Rafique et al. (2015) were even more promising. Shoot segments $(5-7 \mathrm{~mm})$ that were grown on medium for 1 week provided a source of uniform shoot tips. Shoot tips were then excised (1-5 to $2 \mathrm{~mm}$ ) and treated with $1 / 2$ strength MS for one day, $0.5 \mathrm{M}$ sucrose for one day, a loading solution with 2 $\mathrm{M}$ glycerol + $1.6 \mathrm{M}$ sucrose for $30 \mathrm{~min}$, PVS2 for $30 \mathrm{~min}$, and then plunged into LN on V-cryoplates. Regrowth levels were between 57 and $100 \%$ for 10 sugarcane cultivars (Rafique et al., 2015).

The available literature on sugarcane cryopreservation led us to believe that we could readily adopt one of the published methods to implement sugarcane cryopreservation at NLGRP. Our goals in this research were to improve surface sterilization and antibiotic treatments to eliminate bacterial contamination in in vitro sugarcane cultures and to identify a droplet-vitrification, encapsulation dehydration and/or V-cryo-plate method that could be used to cryopreserve clonally propagated cultivars of sugarcane in the NPGS.

\section{MATERIALS AND METHODS}

Sugarcane accessions were obtained as apical cane fragments from the USDA-ARS National Germplasm Repository in Miami, Florida (S. officinarum: 'PI 65807', 'PI 88652', 'PI 101029', 'PI 184794', 'PI 241102'; S. barberi: 'PI 181496', 'PI 181504', 'PI 181510'; S. hybrid: 'PI 140523', 'Q 45337' and S. sinense 'PI 29109'). In addition, S. officinarum cultivars ('384', '613', '961', 'СP011372', 'CP841198', 'CP884730') were obtained as in vitro cultured plants from US Sugar (Clewiston, FL). Accessions received as apical cane fragments were surface sterilized in $70 \%$ isopropyl (10 min), followed by $20 \%$ commercial bleach $(8.25 \%$ sodium hypochlorite) (20 min), and rinsed three times in sterile water (10 min each on a shaker). They were then introduced into tissue culture for multiplication. Multiplication medium was Murashige and Skoog (1962), supplemented with $20 \mathrm{~g} \mathrm{~L}^{-1}$ sucrose, $100 \mathrm{mg} \mathrm{L}^{-1}$ myo-inositol, 1 $\mathrm{mg} \mathrm{L}^{-1}$ thiamine $\mathrm{HCl}, 0.1 \mathrm{mg} \mathrm{L}^{-1}$ kinetin, $0.2 \mathrm{mg} \mathrm{L}^{-1}$ benzylaminopurine and $8.0 \mathrm{~g} \mathrm{~L}^{-1}$ of agar.

Cultivars received as in vitro cultures were placed onto MS medium with $50 \mathrm{~g} \mathrm{~L}^{-1}$ sucrose, $0.9 \mathrm{mg} \mathrm{L}^{-1}$ thiamine $\mathrm{HCl}, 0.4 \mathrm{mg} \mathrm{L}^{-1}$ benzylaminopurine, $1 \mathrm{~g} \mathrm{~L}^{-1}$ activated charcoal, $2.5 \mathrm{~g} \mathrm{~L}^{-1}$ gellan gum (Phytotechnology Laboratories, Shawnee Mission, KS, USA) and adjusted to $\mathrm{pH}$ 5.8. When endogenous bacteria were apparent during the multiplication process, shoots were treated with 0 to $500 \mathrm{mg} \mathrm{L}^{-1}$ cefotaxime or 0 to $2000 \mathrm{mg} \mathrm{L}^{-1}$ streptomycin in liquid MS medium with $30 \mathrm{~g} \mathrm{~L}^{-1}$ sucrose medium for 10 days to eradicate bacteria. Before cryoprocessing, shoot cultures were tested for endophyte presence and only shoots that tested negative were used for cryoprocessing.

\section{Droplet-vitrification}

Shoot tips were excised and treated for $24 \mathrm{~h}$ with 0.15 to $0.60 \mathrm{mM}$ glutathione, 0.12 to 
$0.48 \mathrm{mM}$ ascorbic acid, or $8 \mathrm{mM}$ glycine betaine in MS medium with $60 \mathrm{~g} \mathrm{~L}^{-1}$ sucrose, $7 \mathrm{~g} \mathrm{~L}^{-1}$ agar, pH 5.6 to determine the effect of antioxidants on regrowth after cryoprotectant and LN exposure. Shoot tips were then exposed to $2 \mathrm{M}$ glycerol $+0.4 \mathrm{M}$ sucrose for $20 \mathrm{~min}$ at $22^{\circ} \mathrm{C}$ followed by PVS2 at $0^{\circ} \mathrm{C}(30$ or $40 \mathrm{~min})$ or PVS3 (Nishizawa et al., 1993) at $25^{\circ} \mathrm{C}(20$ or 30 min) to optimize cryoprotectant exposure durations with and without LN exposure. Shoot tips were then placed in droplets of vitrification solution on aluminum foil strips and directly plunged into LN. Shoot tips on foils were warmed by immersion in $1.2 \mathrm{M}$ sucrose at $25^{\circ} \mathrm{C}$ for $20 \mathrm{~min}$ and plated onto regrowth medium (MS medium with $30 \mathrm{~g} \mathrm{~L}^{-1}$ sucrose, 0.2 mg L-1 benzylaminopurine, $0.1 \mathrm{mg} \mathrm{L}^{-1}$ kinetin, $1 \mathrm{~mL} \mathrm{~L}^{-1}$ Plant Preservative Mixture (PPM; Caisson Labs, Smithfield, UT, USA), $7 \mathrm{~g} \mathrm{~L}^{-1}$ agar, $\mathrm{pH}$ 5.7) and kept in the dark for 1 week. After 1 week, shoot tips were transferred to MS medium with $34 \mathrm{~g} \mathrm{~L}^{-1}$ sucrose, $6 \mathrm{~g} \mathrm{~L}^{-1}$ agar and 3.5 $\mathrm{g} \mathrm{L}^{-1}$ activated charcoal, pH 5.7 (Paulet et al., 1993) and grown in the light.

\section{Encapsulation-dehydration}

Encapsulation-dehydration experiments were performed as described by Barraco et al. (2011) with the following modifications. Shoot tips were excised and then dipped into 100 or $150 \mathrm{mg} \mathrm{L}^{-1}$ ascorbic acid for $1 \mathrm{~h}$. They were then placed in a solution of $60 \mathrm{~g} \mathrm{~L}^{-1}$ sucrose + MS for $24 \mathrm{~h}$ and encapsulated into calcium-alginate beads. Beads were incubated in $0.75 \mathrm{M}$ sucrose with $15 \mathrm{~g} \mathrm{~L}^{-1}$ citric acid for $24 \mathrm{~h}$ and dehydrated to a moisture content of 18 to $22 \%$ and plunged into LN within cryovials. For regrowth, alginate beads were warmed in $1.0 \mathrm{M}$ sucrose for $15 \mathrm{~min}$ and plated onto $1 / 2$ strength MS supplemented with $20 \mathrm{~g} \mathrm{~L}^{-1}$ sucrose, $1 \mathrm{mg} \mathrm{L}^{-1}$ benzylaminopurine, $3 \mathrm{~g} \mathrm{~L}^{-1}$ activated charcoal, $3 \mathrm{~g} \mathrm{~L}^{-1}$ agar, and $1.25 \mathrm{~g} \mathrm{~L}^{-1}$ Phytagel (PhytoTechnology Laboratories) at $\mathrm{pH}$ 5.6. Beads containing shoot tips were then placed in the dark overnight, replated onto fresh medium, and returned to the dark. Shoots were removed from beads and plated onto fresh medium weekly.

\section{V-cryo-plate}

Sugarcane shoot tips were cryopreserved using the V-cryo-plate method published by Rafique et al. (2015). Shoot segments of PI 140523 were placed onto one of three media for one week to promote uniform shoot tip development. The media were Mus2 ( $1 / 2$ MS + 150 mg L $\mathrm{L}^{-1}$ citric acid, $30 \mathrm{~g} \mathrm{~L}^{-1}$ sucrose, $8 \mathrm{~g} \mathrm{~L}^{-1}$ agar), Mus3 (1/2 MS $+300 \mathrm{mg} \mathrm{L}^{-1}$ PVP 10,000 (Sigma, St. Louis, MO, USA), $30 \mathrm{~g} \mathrm{~L}^{-1}$ sucrose, and $3 \mathrm{~g} \mathrm{~L}^{-1}$ agar), and Mus4 (1/2 MS $+150 \mathrm{mg} \mathrm{L}^{-1}$ citric acid, $100 \mathrm{mg} \mathrm{L}^{-1}$ ascorbic acid, $30 \mathrm{~g} \mathrm{~L}^{-1}$ sucrose, and $3 \mathrm{~g} \mathrm{~L}^{-1}$ Phytagel). After shoot tips were excised from the cultured shoot segments, they were dipped into $100-150 \mathrm{mg} \mathrm{L}^{-1}$ ascorbic acid for $1 \mathrm{~h}$ and transferred to MS medium supplemented with $0.5 \mathrm{M}$ sucrose for 24 $\mathrm{h}$ and subsequently mounted on $\mathrm{V}$ plates. Shoot tips on $\mathrm{V}$ plates were loaded with $2 \mathrm{M}$ glycerol + 1.6 M sucrose for $30 \mathrm{~min}$ and cryoprotected with PVS2 for $30 \mathrm{~min}$ before plunging into $\mathrm{LN}$. For regrowth, cryo-plates were warmed in $1 \mathrm{M}$ sucrose at $25^{\circ} \mathrm{C}$ for $15 \mathrm{~min}$ and shoot tips were then plated onto V-plate recovery medium containing MS medium, $30 \mathrm{~g} \mathrm{~L}^{-1}$ sucrose, $0.01 \mathrm{mg} \mathrm{L}^{-1}$ 2-napththalene acetic acid, $0.1 \mathrm{mg} \mathrm{L}^{-1}$ benzylaminopurine, $3 \mathrm{~g} \mathrm{~L}^{-1}$ agar, and $1.25 \mathrm{~g} \mathrm{~L}^{-1}$ Phytagel. Plates were placed in the dark and shoot tips were replated onto fresh medium after $24 \mathrm{~h}$. Shoot tips were replated every 2 days for the duration of the 7 day dark incubation period, and then placed onto fresh medium and incubated in the light until regrowth was observed.

Two replicates of 10 to 20 shoot tips were tested for each treatment for all cryopreservation experiments.

\section{RESULTS AND DISCUSSION}

A majority of the in vitro cultures introduced from the SHRS did not exhibit contamination during the multiplication process. However, some of the shoot tips from the accessions that were received as in vitro cultures were contaminated with endogenous bacteria during regeneration after LN exposure. Contaminated shoots $(1 \mathrm{~cm})$ from sugarcane cultures '384', '613', '961', 'CP011372', 'CP841198', and 'CP884730' were treated with 0 to $500 \mathrm{mg} \mathrm{L}^{-1}$ cefotaxime or 0 to $2000 \mathrm{mg} \mathrm{L}^{-1}$ streptomycin to eradicate endogenous bacterial contamination. Although none of the antibiotic treatments eradicated the contamination 
from all of the cultures, clean plants of each cultivar were obtained after cefotaxime treatment. Overall, a 10-day exposure to $500 \mathrm{mg} \mathrm{L}^{-1}$ cefotaxime was found to be the most effective across the sugarcane cultivars (Table 1).

Table 1. Percentage of clean Saccharum cultivars after antibiotic treatment for 10 days.

\begin{tabular}{|c|c|c|c|c|c|c|c|c|c|c|c|c|c|}
\hline \multirow{3}{*}{ Cultivar } & \multicolumn{13}{|c|}{ Clean cultures after antiobiotic treatment (\%) } \\
\hline & \multicolumn{6}{|c|}{ Cefotaxime conc. (mg L-1) } & \multicolumn{7}{|c|}{ Streptomycin conc. (mg L-1) } \\
\hline & 0 & 25 & 50 & 100 & 200 & 500 & 0 & 250 & 500 & 1000 & 1500 & 1750 & 2000 \\
\hline 384 & 0 & 0 & 0 & 0 & 15 & 40 & 0 & 0 & 0 & 0 & 0 & 0 & 0 \\
\hline 613 & 50 & 70 & 80 & 100 & 0 & 20 & 0 & 0 & 0 & 0 & 0 & 0 & 0 \\
\hline 961 & 0 & 0 & 0 & 0 & 0 & 20 & 0 & 0 & 0 & 0 & & & \\
\hline СР011372 & 0 & & & & 20 & 70 & 0 & 40 & 0 & 30 & 0 & 10 & 30 \\
\hline CP841198 & 0 & 10 & 0 & 0 & 0 & 5 & 0 & 25 & 0 & 10 & 0 & 0 & 70 \\
\hline CP884730 & 0 & & & & 20 & 60 & 0 & 0 & 40 & 0 & 0 & 20 & 30 \\
\hline
\end{tabular}

Shoot tips ( 1 to $1.5 \mathrm{~mm}$ ) excised directly from multiplied plants of cultivars ' 384 ' and '613' were pretreated with antioxidants $(0.16 \mathrm{mM}$ glutathione or $8 \mathrm{mM}$ glycine betaine) for $24 \mathrm{~h}$ to determine if antioxidant treatment improved regrowth after PVS3 exposure. For cultivar '384', the antioxidant treatment did not improve regrowth levels after 30 min of PVS3 at $25^{\circ} \mathrm{C}$ (Table 2). There was a higher level of regrowth for cultivar 613 after glycinebetaine treatment compared to the untreated control and glutathione treatment (Table 2). Glutathione and ascorbic acid treatments were also tested for cultivar '613' prior to PVS2 and LN exposure (Table 3). Shoot tips treated with ascorbic acid, glutathione, or no antioxidants for $24 \mathrm{~h}$ prior to PVS2 exposure all had between 85 and $94 \%$ regrowth after PVS2 treatment and the highest level of regrowth after LN was obtained for the shoot tips that were not treated with antioxidants (Table 3). The antioxidants tested did not significantly improve the shoot tip regrowth response after PVS2 or PVS3 and LN exposure.

Table 2. Regrowth of shoot tips from two sugarcane cultivars after antioxidant treatment, with or without a 30-min exposure to PVS3.

\begin{tabular}{lcccc}
\hline \multirow{2}{*}{ Antioxidant } & \multicolumn{2}{c}{ Cultivar 384 } & \multicolumn{2}{c}{ Cultivar 613 } \\
\cline { 2 - 5 } & No cryoprotectant & $\mathbf{3 0}$ min PVS3 & No cryoprotectant & 30 min PVS3 \\
\hline $0.16 \mathrm{mM}$ glutathione & $90 \pm 10 \mathrm{a}$ & $50 \pm 10 \mathrm{a}$ & $70 \pm 20 \mathrm{a}$ & $5 \pm 5 \mathrm{a}$ \\
$8 \mathrm{mM}$ glycine-betaine & $80 \pm 28 \mathrm{a}$ & $60 \pm 0 \mathrm{a}$ & $45 \pm 42 \mathrm{a}$ & $45 \pm 7 \mathrm{~b}$ \\
None & $90 \pm 10 \mathrm{a}$ & $70 \pm 10 \mathrm{a}$ & $80 \pm 28 \mathrm{a}$ & $10 \pm 0 \mathrm{a}$ \\
\hline
\end{tabular}

Table 3. Regrowth of shoot tips from sugarcane cultivar '613' after a 24 -h antioxidant preculture followed by a 30-min exposure to PVS2 either with or without LN.

\begin{tabular}{lcc}
\hline Antioxidant treatment & PVS2 30 min & PVS2 30 min + LN \\
\hline $0.15 \mathrm{mM}$ glutathione & $89 \pm 4 \mathrm{a}$ & $0 \pm 0 \mathrm{a}$ \\
$0.30 \mathrm{mM}$ glutathione & $94 \pm 7 \mathrm{a}$ & $7 \pm 7 \mathrm{a}$ \\
$0.60 \mathrm{mM}$ glutathione & $94 \pm 7 \mathrm{a}$ & $17 \pm 5 \mathrm{a}$ \\
$0.12 \mathrm{mM}$ ascorbic acid & $80 \pm 8 \mathrm{a}$ & $16 \pm 8 \mathrm{a}$ \\
$0.24 \mathrm{mM}$ ascorbic acid & $95 \pm 2 \mathrm{a}$ & $11 \pm 8 \mathrm{a}$ \\
$0.48 \mathrm{mM}$ ascorbic acid & $93 \pm 4 \mathrm{a}$ & $13 \pm 8 \mathrm{a}$ \\
None & $91 \pm 3 \mathrm{a}$ & $37 \pm 16 \mathrm{a}$ \\
\hline
\end{tabular}

Shoot tips of cultivars ' 613 ' and ' 961 ' were precultured for $24 \mathrm{~h}$ in MS medium with 60 $\mathrm{g} \mathrm{L}^{-1}$ sucrose and $7 \mathrm{~g} \mathrm{~L}^{-1}$ agar, pH 5.6 (Barraco et al., 2011) and then treated with PVS2 for 30 or 40 min or PVS3 for 20 or 30 min, either with or without LN. The highest regrowth levels were obtained for '613' with the 40 min PVS2 + LN treatment (18\%) and cultivar '961' with 
the 30 min PVS3 + LN treatment (16\%) (Table 4). Although some shoot tip regrowth was observed after the droplet-vitrification procedure, none of the levels were high enough to be considered ready for genebank implementation.

Table 4. Droplet-vitrification of two sugarcane cultivars after a $24 \mathrm{~h}$ preculture in MS with $60 \mathrm{~g} \mathrm{~L}^{-1}$ sucrose, $7 \mathrm{~g} \mathrm{~L}^{-1}$ agar, $\mathrm{pH}$ 5.6, followed by PVS2 or PVS3, either with or without LN.

\begin{tabular}{lcccc}
\hline \multirow{2}{*}{ Treatment } & \multicolumn{2}{c}{ Cultivar 613 } & \multicolumn{2}{c}{ Cultivar 961 } \\
\cline { 2 - 5 } & $-\mathrm{LN}$ & $+\mathrm{LN}$ & \multicolumn{1}{c}{$\mathrm{LN}$} & $+\mathrm{LN}$ \\
\hline 30 min PVS2 & $88 \pm 3 \mathrm{a}$ & $7 \pm 3 \mathrm{a}$ & $98 \pm 3 \mathrm{a}$ & $5 \pm 5 \mathrm{a}$ \\
40 min PVS2 & $93 \pm 3 \mathrm{a}$ & $18 \pm 6 \mathrm{a}$ & $85 \pm 7 \mathrm{a}$ & $15 \pm 12 \mathrm{a}$ \\
20 min PVS3 & $87 \pm 3 \mathrm{a}$ & $0 \pm 0 \mathrm{a}$ & $92 \pm 4 \mathrm{a}$ & $2 \pm 2 \mathrm{a}$ \\
30 min PVS3 & $83 \pm 7 \mathrm{a}$ & $5 \pm 5 \mathrm{a}$ & $94 \pm 2 \mathrm{a}$ & $16 \pm 8 \mathrm{a}$ \\
\hline
\end{tabular}

Encapsulation-dehydration methods were employed to cryopreserve three clean accessions of Saccharum. Regrowth levels after LN exposure were $0 \%$ for S. officinarum 'PI 88652', 20\% for S. sinense 'PI 29109', and 50\% for S. officinarum 'PI 65807' (Table 5).

Table 5. Cryopreservation of Saccharum shoot tips using an encapsulation-dehydration procedure. Mean regrowth levels after LN exposure.

\begin{tabular}{lcc}
\hline Accn. & Taxon & Shoot tip regrowth (\%) \\
\hline PI 29109 & S. sinense & $20 \pm 20 \mathrm{a}$ \\
PI 65807 & S. officinarum & $50 \pm 10 \mathrm{a}$ \\
PI 88652 & S. officinarum & $0 \pm 0 \mathrm{a}$ \\
\hline
\end{tabular}

Shoot segments were grown on three different media (Mus2, Mus3, and Mus4) for one-week prior to shoot tip excision and use in the V-cryo-plate cryopreservation procedure using S. hybrid 'PI 140523'. The highest regrowth (25\%) after LN was obtained when shoot tips were grown on Mus2 medium for one week. Shoot tips cultured on Mus3 had regrowth levels of $18 \%$ and shoot tips cultured on Mus4 had regrowth levels of $9 \%$ after LN exposure (Table 6).

Table 6. Comparison of culture medium to produce uniform shoot tips prior to V-cryo-plate cryopreservation. Mean regrowth levels after LN exposure for Saccharum hybrid 'PI 140523'.

\begin{tabular}{lc}
\hline Shoot uniformity medium & Shoot tip regrowth (\%) \\
\hline Mus2 & $25 \pm 23 \mathrm{a}$ \\
Mus3 & $18 \pm 13 \mathrm{a}$ \\
Mus4 & $9 \pm 10 \mathrm{a}$ \\
\hline
\end{tabular}

The V-cryo-plate cryopreservation method was also tested for seven Saccharum accessions from S. officinarum ('PI 101029', 'PI 184794', 'PI 241102'), S. barbari ('PI 181496', 'PI 181504', 'PI 181510'), and $S$. hybrid ('Q 45337') and regrowth levels ranged from 0 to $10 \%$ after cryo-exposure. The levels of regrowth obtained using the V-cryo-plate method were not deemed to be high enough for additional cultivar tests (Table 7).

Our extensive efforts (data herein and data not shown) to cryopreserve shoot tips of sugarcane did not yield the expected results. Based on our initial literature reviews, we had anticipated that sugarcane cryopreservation would be straightforward and easily implemented in our collection. To the contrary, we found that our experiments yielded cryopreservation regrowth levels that were low, despite our efforts to optimize key parameters and to include supplements such as antioxidants. 
Table 7. Regrowth level of diverse Saccharum accessions after cryopreservation using the Vcryo-plate method.

\begin{tabular}{lcc}
\hline Accn. & Taxon & Shoot tip regrowth (\%) \\
\hline PI 101029 & S. officinarum & $0 \pm 20 \mathrm{a}$ \\
PI 181496 & S. barberi & $8 \pm 10 \mathrm{a}$ \\
PI 181504 & S. barberi & $0 \pm 0 \mathrm{a}$ \\
PI 181510 & S. barberi & $10 \pm 0 \mathrm{a}$ \\
PI 184794 & S. officinarum & $5 \pm 3 \mathrm{a}$ \\
PI 241102 & S. officinarum & $0 \pm 0 \mathrm{a}$ \\
Q 45337 & S. hybrid & $3 \pm 3 \mathrm{a}$ \\
\hline
\end{tabular}

It is likely that the age and quality of the in vitro cultures plays a significant role in the success of the procedure. Many of our in vitro cultures had been subcultured for one or more years prior to their use. In addition, shoot tip uniformity and a high degree of genetic variability among accessions may have impacted our regrowth levels. Future success may require the use of plant materials that are freshly introduced into culture and free of endogenous contamination. In addition, explant size, pretreatment conditions, cryoprotectant exposure, and regrowth medium may need to be further optimized using several diverse Saccharum species to help ensure that the developed methods are widely applicable.

\section{ACKNOWLEDGEMENTS}

This research was funded in part by a grant provided by US Sugar Corporation.

\section{Literature cited}

Barraco, G., Sylvestre, I., and Engelmann, F. (2011). Comparing encapsulation-dehydration and dropletvitrification for cryopreservation of sugarcane (Saccharum spp.) shoot tips. Sci. Hortic. (Amsterdam) 130 (1), 320-324 https://doi. org/10.1016/j.scienta.2011.07.003.

Eksomtramage, T., Paulet, F., Guiderdoni, E., Glaszmann, J.C., and Engelmann, F. (1992). Development of a cryopreservation process for embryogenic calluses of a commercial hybrid of sugarcane (Saccharum sp.) and application to different varieties. Cryo Lett. 13, 239-252.

Finkle, B.J., and Ulrich, J.M. (1982). Cryoprotectant removal temperature as a factor in the survival of frozen rice and sugarcane cells. Cryobiology 19 (3), 329-335 https://doi.org/10.1016/0011-2240(82)90161-4. PubMed

González-Arnao, M.T., and Engelmann, F. (2006). Cryopreservation of plant germplasm using the encapsulationdehydration technique: review and case study on sugarcane. Cryo Letters 27 (3), 155-168. PubMed

González-Arnao, M.T., Urra, C., Engelmann, F., Ortíz, R., and de la Fe, C. (1999). Cryopreservation of encapsulated sugarcane apices: effect of storage temperature and storage duration. Cryo Lett. 20, 347-352.

Kaya, E., and Souza, F.V.D. (2017). Comparison of two PVS2-based procedures for cryopreservation of commercial sugarcane (Saccharum spp.) germplasm and confirmation of genetic stability after cryopreservation using ISSR markers. In Vitro Cell. Dev. Biol. Plant 53 (4), 410-417 https://doi.org/10.1007/s11627-017-9837-2.

Martínez-Montero, M.E., González-Arnao, M.T., Borroto-Nordelo, C., Puentes-Díaz, C., and Engelmann, F. (1998). Cryopreservation of sugarcane embryogenic callus using a simplified freezing process. Cryo Lett. 19, 171-176.

Melo, C.G., Barbosa, M.H.P., Motoike, S.Y., Sabino, M.V., Ventrella, M.C., Peternelli, L.Z., and Oliveira, M.A.R. (2011). Preculture sugarcane tissue in sucrose-supplemented culture medium to induce desiccation tolerance. Crop Breed. Appl. Biotechnol. 11 (4), 320-329 https://doi.org/10.1590/S1984-70332011000400005.

Murashige, T., and Skoog, F. (1962). A revised medium for rapid growth and bioassays with tobacco cell cultures. Physiol. Plant. 15 (3), 473-497 https://doi.org/10.1111/j.1399-3054.1962.tb08052.x.

Nishizawa, S., Sakai, A., Amano, Y., and Matsuzawa, T. (1993). Cryopreservation of asparagus (Asparagus officinalis L.) embryogenic suspension cells and subsequent plant regeneration by vitrification. Plant Sci. 91 (1), 67-73 https://doi. org/10.1016/0168-9452(93)90189-7.

Nogueira, G., Pasqual, M., and Scherwinski-Pereira, J.E. (2013). Survival of sugarcane shoot tips after cryopreservation by droplet-vitrification. Pesqui. Agropecu. Bras. 48 (11), 1524-1527 https://doi.org/10.1590/S0100-204X201300 1100014. 
Paulet, F., Engelmann, F., and Glaszmann, J.-C. (1993). Cryopreservation of apices of in vitro plantlets of sugarcane (Saccharum sp. hybrids) using encapsulation/dehydration. Plant Cell Rep. 12 (9), 525-529 https://doi.org/10.1007/ BF00236101. PubMed

Rafique, T., Yamamoto, S., Fukui, K., Mahmood, Z., and Niino, T. (2015). Cryopreservation of sugarcane using the V cryo-plate technique. Cryo Letters 36 (1), 51-59 https://doi.org/10.17660/ActaHortic.2015.1101.14. PubMed

Sakai, A., Kobayashi, S., and Oiyama, I. (1990). Cryopreservation of nucellar cells of navel orange (Citrus sinensis Osb. var. brasiliensis Tanaka) by vitrification. Plant Cell Rep. 9 (1), 30-33 https://doi.org/10.1007/BF00232130. PubMed 
